\title{
CONSECUENCIAS ANTROPOLÓGICAS DE LA COMUNICACIÓN DE MASAS, UN ANÁLISIS TEÓRICO-EMPÍRICO DEL CASO ARGENTINO
}

\author{
LUCIANO H. ELIZALDE \\ FACULTAD de Ciencias de La Información. Universidad Austral. CONICET
}

\section{Resumen}

Los modelos de estudio de los efectos de los medios de comunicación de masas no han podido explicar con suficiente claridad de qué manera éstos afectan e influyen en la vida de las personas y de sus sociedades. El objetivo del trabajo es presentar un modelo de explicación de los efectos de los medios de comunicación de masas que supere algunas debilidades de los modelos convencionales. Para hacerlo, se utilizaron tres puntos de vista complementarios: el análisis histórico, el microsociológico y el comunicativo. Estas tres líneas confluyen en el análisis de unas consecuencias que pueden ser definidas como "antropológicas" ya que son cambios que los medios generaron no sólo sobre una sociedad sino sobre la especie humana. Finalmente, el método de trabajo ha sido el de la construcción de teoría por medio de uso de datos cualitativos.

\section{Abstract}

The models for studying the effects of the mass media have proven unable to explain with sufficient clarity how it affects and influences peoples' lives and their societies. The aim of this paper is to present a model for explaining the effects of the mass media while eschewing some weaknesses of the traditional models. To do so three complementary points of view are used: historical, microsociological and communicative analysis. These three lines come together in the analysis of consequences that could be defined as "anthropological", since they are changes brought about by the media not only in a given society but in the human species itself. The working method used is theory construction by means of qualitative data. 


\section{INTRODUCCIÓN}

\section{Objetivos y planteo del problema}

Tanto críticos como defensores de los medios de comunicación pública colectiva apoyan sus argumentos respectivos en alguna de las mil conjeturas acerca de los efectos que estos medios generan en la sociedad y en sus miembros. El problema de los efectos que los medios tienen sobre la sociedad es un tema que no sólo activa el interés racional, sino que produce reacciones emocionales. Se podría decir con tranquilidad que la teoría de los efectos de los medios sobre la sociedad, la cultura y las personas, es uno de los aportes más populares de las ciencias sociales al conocimiento de sentido común. Sin embargo, se está a gran distancia de alcanzar explicaciones precisas. Los modelos teóricos que dan forma a esas hipótesis no han permitido esclarecer aún con cierto detalle la manera en que los medios de comunicación transforman a las personas y a sus relaciones sociales. Mucho menos estos modelos tienen la capacidad de mostrar y de explicar el entramado de relaciones entre los medios y la sociedad, relación responsable de la formación de las principales características de las organizaciones informativas y de sus actividades cotidianas y de los patrones de conducta de grupos y de personas sociales. Habermas lo expresó con cierta claridad al decir que los modelos teóricos aplicados al problema no se han mostrado demasiado concluyentes al respecto'.

Teniendo en cuenta esta debilidad y, al mismo tiempo, la necesidad de superarla, en este trabajo se pretende elaborar una explicación de los procesos de determinación que los medios producen sobre la sociedad y que la sociedad produce sobre los medios. Para hacerlo se estudiará el proceso de institucionalización mediática. Este proceso de institucionalización-considerado como un supuesto básico subyacente en los modelos teóricos convencionales - será aquí el objeto de estudio, en tanto y en cuanto representa el proceso de mediatización pública colectiva que experimentaron las sociedades modernas.

¿Cuáles son las causas que llevaron a que los modelos de explicación de los efectos de los medios en tantas décadas no fuesen eficientes? Son varias, aunque las más importantes sólo podrían ser tres: cuestiones teóricas -uso de modelos teóricos poco complejos en relación con el problema que deben resolver-, epistemológicas -dominio del punto de vista objetivista-y metodológicas -monopolio de los diseños experimentales y de campo. Desde el punto de vista teórico, los modelos de explicación de las consecuencias que ha producido la comunicación de masas sobre las sociedades modernas no suelen recorrer la trayectoria de la mediatización sino que la consideran como un supuesto. Avanzan desde la hipótesis de que las personas y los grupos que investigan experimentan un cierto grado de mediatización con la realidad gracias a

\footnotetext{
"Los estudios sobre los medios de comunicación dan información en cierto modo fiable acerca del marco institucional y de la estructura, así como sobre la forma de trabajo, la configuración de los programas y la utilización de los medios; pero las afirmaciones sobre los efectos de los medios siguen siendo inseguras, incluso una generación después de Lazarsfeld." (Habermas, 1998, p. 458).
} 
los medios de comunicación de masas. Dicho supuesto los lleva a que sólo busquen los efectos como sinónimo de modificaciones que deben ser diferenciados de otros cambios no originados en los medios de comunicación. De esta manera, por ejemplo, en relación con la problemática de la violencia producida por los medios, las conclusiones de los estudios con modelos experimentales, cuasiexperimentales y de campo fluctúan en un espectro muy amplio que va desde considerar que los medios no reproducen conductas violentas en los receptores hasta afirmar que las determinan (Felson, 1996; Gunter, 1996). El problema que surge es el de la relación entre procesos de comunicación masiva y procesos de comunicación no masiva: en qué medida los procesos de exposición ante representaciones de violencia, de conductas morales obscenas o de situaciones culturales extrañas no han sido tomadas de la realidad no mediática, experimentadas directamente y no en los medios de comunicación. En segundo lugar, lo más común es que las teorías que explican cómo la comunicación de masas ha cambiado la sociedad y a sus miembros se apoyan en hipótesis de una epistemología objetivista (Bourdieu, 1995; Habermas, 1988). De este modo, sus resultados reportan una realidad que sólo es posible explicar desde el punto de vista del observador externo, el que no ha participado en el hecho social. Hay pocos trabajos con validez científica que hayan aportado un punto de vista subjetivo acerca de la determinación de los medios sobre la audiencia. Por otro lado, el punto de vista objetivista produce una imagen de este proceso de mediatización que lleva a pensar en que la comunicación de masas es relevante sólo para algunos sistemas sociales: por ejemplo, para el económico por el impacto de la publicidad o para el sistema político, en relación con las campañas electorales. Ambas situaciones llevan a interrogarse sobre qué le sucede realmente a las personas que se exponen y se relacionan con los medios en sentido amplio, cómo afectan su vida en tanto existencia histórica concreta y qué consecuencias tiene esto sobre sus vidas. Por último, con pocas excepciones (McLuhan, 1964; Ong, 1961; Innis, 1942, 1951) la investigación sobre efectos no ha pasado del uso de estrategias experimentales y de campo, que sólo resuelven problemas vinculados con cambios sociales o psíquicos en contextos espaciales y temporales muy precisos. Para no caer en los extremos de los autores acusados de deterministas tecnológicos ni tampoco quedarse en la medición de las consecuencias que sobre las personas sociales la acción de consumir cierto anuncio publicitario o determinada campaña de propaganda o la cobertura de noticias, es necesario desarrollar un modelo epistemológico, metodológico y teórico que incorpore la posibilidad de comprender los cambios en las conductas o en las actitudes de los seres humanos, pero sin que estos cambios dejen de estar integrados a la cultura y a la vida social.

En definitiva y de acuerdo con estas debilidades de las teorías de efectos, el objetivo más importante de este trabajo, entonces, es llegar a una definición del proceso latente que soporta la estructura de los efectos psicológicos y sociales de los medios de comunicación: esto es el proceso de mediatización en tanto institucionalización de la comunicación de masas. El supuesto de este estudio es que no podría haber ningún tipo de determinación de los medios de comunicación sobre la sociedad sin el previo desarrollo de un proceso de institucionalización o mediatización colectiva. Y que este proceso de institucionalización es lo que forma la relación más permanente que las personas tienen con los medios. Por medio del ejemplo histórico del caso de la radio y de la televisión en la Argentina se tratará de reconstruir el proceso de institucionalización de la comunica- 
ción de masas para que sirva como base sobre la cual estudiar efectos más concretos y particulares. Esto significa que no se pondrá a prueba una hipótesis, sino que se buscará la manera de reformular y reconstruir el concepto de mediatización de acuerdo con el resultado del análisis de los datos históricos que se analizarán.

Desde este planteo, el problema del estudio puede plantearse de la siguiente manera: ¿Qué consecuencias ha generado la mediatización sobre la cultura, la sociedad y las personas? ¿ Qué aspectos de la mediatización son los más importantes para influir sobre la realidad social? La respuesta a estos interrogantes se expondrá en los siguientes pasos: primero, se mostrarán las categorías y las dimensiones que conforman la estructura de los medios de comunicación de masas desde un punto de vista de los receptores y cuáles son las dimensiones básicas de la realidad social que los medios podrían modificar, (2); segundo, se analizará el desarrollo de las consecuencias y de las determinaciones que la radio y que la televisión produjeron en la Argentina, como un modo de construir un modelo de análisis que se origine no sólo en los conceptos sino en la realidad empírica, (3).

\section{Metodología}

El período que se utilizó para extraer datos empíricos, abarca casi un siglo: desde finales del siglo XIX hasta los años noventa del siglo XX. Durante este tiempo, la Argentina -como también muchas otras naciones - se encontró con una nueva manera de comunicar, gracias a dos tecnologías: la radio, en primer lugar, y luego, la televisión. El trabajo se sustenta en el análisis de tres diferentes tipos de datos históricos: datos de biografías acerca del consumo de medios; análisis de las leyes que instauraron el funcionamiento de los medios y datos de los historiadores acerca de la vida cotidiana en la Argentina. En primer lugar, analizaron más de 100 biografías realizadas a personas de más de 60 años, como complemento de los estudios de recepción desarrollado sobre jóvenes entre los años 1995 y 1999 (Elizalde, 1998, 1999a, 1999b, 2000). El objetivo del relato biográfico fue alcanzar una descripción de lo que recordaban las personas de sus experiencias con los medios de comunicación en sus respectivos hogares. Segundo, se usó el universo de normas positivas sancionadas entre 1875 y 1990 para regular diferentes aspectos de la comunicación de masas (periodismo, publicidad, información de Estado, etc.). El punto de vista del análisis de las leyes no fue jurídico sino sociológico. Finalmente, se utilizó para complementar estos datos primarios, el análisis realizado por los historiadores de la vida cotidiana y de la historia institucional de la Argentina (Devoto y Madero, 1999).

\section{DIMENSIONES MEDIÁTICAS Y NIVELES DE LA REALIDAD SOCIAL.}

\section{La comunicación de masas desde un punto de vista antropológico}

Desde un punto de vista teórico, la mediatización por la que han pasado las sociedades es un fenómeno que podría definírselo de antropológico en tanto y en cuanto se ha transformado en una experiencia más o menos normal para la totalidad de los miembros de la especie 
humana. Desde la utilización de la imprenta como medio de producción de libros, es decir, de mensajes producidos estandarizadamente, hasta la televisión y las nuevas tecnologías digitales, las sociedades humanas se han visto modificadas por la aparición y la utilización de medios que producen, distribuyen y permiten el consumo de conocimiento social de manera tal que los límites físicos y biológicos de los seres humanos no obstaculizan la relación con este conocimiento. La mediatización, en sentido estricto, es el proceso histórico de incorporación y de uso social de medios técnicos en la vida cotidiana. Los medios técnicos permiten alcanzar ciertos objetivos. Permiten realizar cierta actividad compleja de modo más simple y de manera más económica. La realidad humana, poco a poco, ha sido mediatizada. Esta afirmación es trivial si se consideran todos tanto años de reflexión filosófica, antropológica y sociológica sobre la técnica y sus efectos. Sin embargo, aún no ha sido utilizado por la sociología y por la antropología de la comunicación de masas para explicar las consecuencias de los medios de comunicación de masas sobre la especie.

La mediatización no sólo incluye dimensiones técnicas. La técnica se introduce como resultado de un conjunto de procesos culturales (patrones de sentido, categorías, planes de acción), sociales (cambios económicos, políticos, jurídicos, educativos, etc.) y personales (de conciencia, corporales, de conductas). En el caso particular de la comunicación de masas, estos procesos institucionales y personales permitieron instalar ciertas prácticas de producción, de distribución, de recepción y de consumo de productos simbólicos, de conocimiento a escala, rompiendo los límites espacio temporales que tenían los seres humanos para conocer la realidad y para experimentarla. Desde un punto de vista antropológico, es decir, para la especie humana en su conjunto, la comunicación de masas es un proceso de producción sistemático de conocimiento social que se distribuye gracias a una tecnología que permite dos cosas: por un lado, alcanzar audiencias que por su cantidad o por la diferencia de su ubicación geográfica no podrían ser reunidas en un espacio cerrado ni tendrían capacidad sus miembros de tomar contacto perceptivo y sensitivo directo entre ellos; y por otro, que el consumo del conocimiento producido y distribuido por estas organizaciones más o menos especializadas, no pueda ser controlado por quienes lo producen: es decir, el proceso de reconocimiento y de recepción que realizan las personas que cumplen el rol de receptores no puede ser evaluado por los productores o por los distribuidores en tanto el conocimiento público se lo consume en ámbitos privados, de manera individual o grupal.

En resumen, a priori del análisis y de la comparación de los datos históricos y sociológicos, se define la mediatización como un proceso característico de la especie humana en un momento específico de su histórica, que consiste en el proceso de instalación de medios técnicos -intelectuales y materiales - de producción, de distribución, de consumo y de recepción de conocimiento social. Este conocimiento social ha sido y es valorado por quienes lo consumen porque les permite realizar ciertas tareas y actividades sociales: conocer mejor el entorno social, político, económico; entretenerse, divertirse y consumir el tiempo, es decir, dejar el estado de aburrimiento. Pero además, este conocimiento social fue producido y distribuido con la intención de que llegue a ser consumido por la mayor cantidad de público posible. Esto es el resultado de un proceso de democratización social (Elias, 1995:133 y ss.) que se fue dando progresivamente en las sociedades occidentales y que dio lugar al proceso de mediatización. Aunque, una vez institucionalizado, este pro- 
ceso de mediatización impulsó y desarrolló la democratización social. Esta democratización social no es lo mismo que la democratización del sistema político. Según el concepto de Elias, las sociedades occidentales comenzaron a incluir una participación de grupos sociales menos poderosos desde el punto de vista económico, cultural y militar. Una conciencia social que promovía la "igualdad" como canon o pauta de acción se hizo normal. Y una distribución de conocimiento para una mayor cantidad y diversidad de personas sociales fue parte de este proceso de democratización social. Para esto comenzaron a funcionar organizaciones que se especializaron en gestionar ciertos medios técnicos y tecnológicos para producir y distribuir conocimiento sobre situaciones de la vida cotidiana y normal de la sociedad.

\section{Dimensiones de los medios de comunicación desde la perspectiva de la recepción}

De acuerdo con lo anterior, no sólo es posible, sino absolutamente necesario definir la comunicación de masas desde un punto de vista subjetivo, es decir, de sus participantes. Y el estudio de recepción realizado en la Argentina con jóvenes de entre 18 y 25 años, entre los años 1995 y 2000 (Elizalde, 1999a, 1999b, 2000) sirvió, entre otras cosas, para la construcción de un modelo estructural de medio de comunicación de masas de acuerdo con las dimensiones identificadas por los mismo receptores. Estas dimensiones son categorías subjetivas, es decir, aspectos reconocidos por los receptores de modo espontáneo ante la propuesta de discutir la manera en que ellos interactuaban con los medios en el contexto de la vida cotidiana. Las dimensiones identificadas y reconstruidas fueron las siguientes:

Tecnología de fransmisión y de recepción de señales. En las relaciones objetivas con los medios aparecen las tecnologías. La tecnología, en tanto objeto físico con el cual las personas interactúan, es una dimensión central de los medios para los receptores. Desde el punto de vista económico - de acuerdo con los costos que tiene adquirirla - pero también desde una perspectiva relacional y estética, la tecnología de la comunicación cumple una función central en la relación con los receptores. Desde el punto de vista histórico, aparece una nueva técnica o se adaptan varios elementos de otras más antiguas para transmitir y para recibir señales físicas que pueden ser decodificadas por los sentidos humanos y transformadas en conocimiento (conjuntos de símbolos con sentido y capacidad de orientación). La técnica se considera como un objeto social con el que las personas sociales establecen relaciones problemáticas. El uso, la apropiación, el control por ciertas personas, la decisión acerca de su adquisición, ubicación, etc. son algunos de los problemas que surgen en esta dimensión.

Saberes culturales. Los receptores interactúan y al mismo tiempo seleccionan saberes culturales que los preceden en tiempo y que tienen un grado de objetividad superior al del conocimiento que las personas tienen en sus conciencias. Deporte, noticias políticas, de economía, de interés humano, publicidad, relatos amorosos, dramáticos, trágicos, saberes contemporáneos y clásicos, etc.

Textos y géneros. Se enmarca a los saberes o conocimientos no especializados dentro de formas estéticas y estilísticas para ayudar a que las personas que cumplen el papel de receptores pue- 
dan interpretar mejor, de acuerdo con pautas culturales y sociales de sentido común, lo que perciben $o$ atienden. De realidad y de ficción, por un lado, y serios y no serios, por otro, son los modos reconocidos por los receptores jóvenes (Elizalde, 1999a, 2000).

Los textos - de realidad o de ficción, serios o no serios - son identificados por personajes o personas públicas. Periodistas, relatores, conductores, actores, actrices, son las funciones más importantes de estas personas que provocan la atención de la audiencia.

Hese cuiturales, sociales y personales. Las personas que consumen cotidianamente los conocimientos produçidos y distribuidos por las organizaciones profesionales, lo utilizan para diferentes objetivos. Éstos no son siempre individuales como pretende decir la teoría de los usos y gratificaciones. Se reconocen los de informarse, entretenerse, evadirse y pasar el tiempo (Elizalde, 2000).

En resumen, para los receptores, un medio de comunicación de masas es un sistema tecnológico de producción, distribución y consumo de conocimiento social culturalmente definido, organizado en textos, en géneros y en modos discursivos para facilitar la comprensión de los receptores, que hacen más o menos conocidas ("famosas") a ciertas personas -con lo cual incorporan cierto grado de intersubjetividad al proceso, y que pueden ser usados -contenidos, textos, géneros y personajes - para fines diferentes, de acuerdo con las necesidades o con las costumbres de las audiencias.

\section{Niveles de la realidad social}

La otra parte del modelo básico de determinación mediática es la realidad que ha de ser modificada. No es posible explicar los procesos de determinación de los medios sin tener una imagen de la realidad social que éstos modifican. El modelo de realidad social que se utilizará está definido de acuerdo con varios autores centrales en la teoría sociológica (Bourdieu, 1983, 1991; Elias, 1990, 1995; Touraine, 1995). Las dimensiones de la realidad social aquí consideradas son:

Relaciones objefivas y estructurales. Los seres humanos encuentran límites y posibilidades para actuar, para sobrevivir y realizarse, dentro de ciertas reglas morales, de poder, de significación, pero que no pueden modificar porque están fuera de su control personal e interpersonal. Hay grupos - dirigentes o dominantes-que pueden tener el control de crear, disolver o de anular las reglas que establecen estas relaciones objetivas.

Por otro lado, los seres humanos participan de relaciones que pueden controlar, por momentos, pero que de hecho, son relaciones construidas y creadas por el vínculo, el contacto y la interacción entre los participantes. Estas relaciones responden a reglas, pero las reglas pueden ser gestionadas por quienes participan de la relación.

El concepto de persona social permite -en contraposición al de sujeto, agente o individuo - integrar varias dimensiones: el cuerpo como algo socializado, la conciencia -ya 
sea en forma de pensamiento consciente o inconsciente- y las conductas racionales o emocionales. En definitiva, la persona social puede ser identificada y analizada por medio de la identificación de las acciones que produce, de su pensamiento, es decir, de las categorías cognitivas con las que percibe, clasifica y califica la realidad, y por sus pautas emocionales de conducta. Elias (1990:223 y ss) decía que estos tres elementos conforman el área de experiencia de la persona. Y que no es posible llegar a un análisis detallado y realista de la realidad social si sólo se analizan las acciones de las personas sociales.

Por medio de este nivel de realidad es posible identificar y diferenciar aquellas formas básicas de relación, de comportamiento y de percepción que dependen del ambiente histórico y social de los seres humanos, de aquellos otros que se comparten con el resto de los seres humanos y que, entonces, no fueron desarrollados culturalmente, sino que dependen de la estructura filogenética. Los etólogos (Lorenz, 1993; Eibl Eibesfeldt, 1993) estudian las coordinaciones filogenéticas, es decir, heredadas por seres humanos contemporáneos de otros seres humanos de generaciones anteriores. La etología como estudio biológico de la conducta humana se sustenta en el análisis de los mecanismos desencadenantes innatos y de los mecanismos motivadores comunes a la especie humana. Los primeros son complejos de activación de relaciones, conductas, percepciones y emociones que necesitan de un estímulo externo para ser activados (por ejemplo, la conducta agresiva). Los mecanismos motivadores, por otro lado, no necesitan de este estímulo externo: puede activarse una conducta regulada por el propio cuerpo (por ejemplo, conductas dirigidas a saciar el hambre, la sed, el sueño o la sexualidad).

En definitiva, el proceso de institucionalización de los medios colectivos de comunicación y de información, durante el siglo XX, afectó y modificó algunos o todos los niveles de realidad social antes expuestos. Para explicar mejor la relación entre mediatización y realidad social, es necesario darle contenido histórico a ambas dimensiones y relacionarlas para comprender cómo el complejo de los medios técnicos de producción, distribución y consumo de información modificaron la realidad social. Esta modificación de la realidad social por los medios se realizó de modo muchas veces inconsciente para los protagonistas, de forma paulatina, a lo largo de décadas, años o meses, lo cual originó que se transformara en la estructura latente -o en el frame cultural- de los procesos de influencia particular que se sucedieron y suceden en la vida cotidiana.

\section{LAS DIMENSIONES DE LA MEDIATIZACIÓN; LA RADIO Y LA TELEVISIÓN EN LA ARGENTINA.
LAS CONSECUENCIAS DE IA MEDIATIZACIÓN SORRF LA REAIIDAD SOCIAL}

Definir qué es un medio de comunicación de masas es un poco más complejo de lo que parece a simple vista. Sobre todo, porque implica considerar una serie de dimensiones de la realidad que, desde el punto de vista del sentido común, suelen pasar inadvertidas. Por otro lado, desde una teoría social que pretenda explicar este proceso, como antes se dijo, es normal que se propongan definiciones que sólo tengan como prioridad alcanzar algunas de todas las dimensiones de la realidad de la comunicación de masas. 
La mediatización ha sido y es un proceso social desarrollado y formado a largo plazo. Ha sido análogo, en varios aspectos, a los procesos de industrialización, de democratización, de estatización o de racionalización que ha estudiado y estudia la ciencia social. Significa, exactamente, que personas, grupos de personas, organizaciones y sistemas sociales (económico, político, educativo, de seguridad, religioso, etc.) han tipificado y legitimado el uso de unos medios para acceder a cierto tipo de conocimiento social de tipo impersonal. Esta experiencia social fue iniciada con la escritura pero se expandió y se repitió en la medida en que también aumentó la cantidad de medios tecnológicos que las personas pueden utilizar para diferentes funciones. Desde el punto de vista de la mediatización como experiencia social, los medios de difusión transformaron muchos aspectos de las formas de vida en las sociedades del siglo XX. A continuación se analizarán las diferentes dimensiones de la realidad social y los efectos que la mediatización tuvo sobre ésta.

\section{Mediatización y realidad social objetiva: relaciones mutuas de determinación}

Antes y durante el proceso de la institucionalización de la radio como medio de comunicación utilizado colectivamente, diversos aspectos que forman la realidad social objetiva determinaron este proceso de institucionalización. Al mismo tiempo, y de manera paulatina, décadas después, el proceso de mediatización colaboró en los cambios que se producirían en la realidad social objetiva. Para ejemplificar el proceso de cambio en ambos planos -en el de mediatización y en el de la realidad social objetiva- se considerará a las dimensiones de los medios de comunicación en tanto "mecanismos" (Elster, 1989:13 y ss.) de transformación, producción y de estabilización de los cambios en la realidad personal, social y cultural.

El cambio más visible y más claro para quienes participaban en el proceso de institucionalización de la radio fue la inserción de una nueva tecnología en la vida pública y privada de modo cada vez más rutinario. Las relaciones sociales objetivas a finales del siglo XIX y a principios del siglo XX, aceleraron el proceso de mediatización hasta tal punto, que en cierto momento del siglo pasado, esta mediatización, sus agentes y sus reglas se transformaron en parte de las relaciones sociales objetivas. Los grupos sociales (políticos, empresarios, militares, intelectuales, etc.) que tenían capacidad para producir reglas de regulación y de legitimación, impulsaron el proceso de mediatización social que estaba desarrollándose, aunque de un modo menos masivo, por medio del libro y de la prensa de masas.

¿Qué relaciones de determinación se desarrollaron a lo largo de unos cien años entre las dimensiones que forman los medios de comunicación colectiva y la realidad social? En primer lugar, para que comience el proceso de mediatización es necesario que se conceptualice y se intente instalar para ciertos fines una tecnología correspondiente. Pero este hecho también es bastante más complejo de lo que se supone. Las tecnologías no se instalan en un vacío social. En el caso de la radio, los grupos sociales dirigentes la definieron, antes de 1920, como una técnica para ser usada al servicio de la seguridad y de la guerra. Esto no fue algo privativo de la Argentina: en otras partes del mundo (Inglaterra, Francia, Alemania, Estados Unidos), la radio también comenzó a funcio- 
nar dentro de la organización burocrática militar y a cumplir funciones de seguridad con enemigos externos ${ }^{2}$. Sólo después de algunas acciones experimentales de grupos de aficionados, pero que pertenecían a grupos dirigentes, se percibió a la radio como un medio de comunicación cultural ${ }^{3}$.

En el caso de la televisión, en cambio, su proceso de institucionalización se desarrolló guiado por el modelo de la radio, aunque el control y la conceptualización del medio no estuvieron bajo el control de la burocracia militar sino de la que era controlada por los grupos políticos identificados con el peronismo. La televisión fue concebida como un medio experimental y estéticamente sofisticado, pero rápidamente se modificó esta orientación y se preparó para que cumpliese funciones políticas de generación de lealtad y de consenso social. Para alcanzar este objetivo, los grupos dirigentes crearon reglas de regulación y de producción orientadas a que la institucionalización de la radio y de la televisión se transformaran en organizaciones empresariales. La diferencia entre ambos medios, fue que la llegada de la televisión -nacida en medio de la segunda presidencia de Perón (1950) - estuvo precedida por la experiencia de la radio, lo cual dejó pocas dudas sobre cuál debía ser su cometido dentro de la clase dirigente: además de producir rentabilidad económica estaba organizada, fundamentalmente, para generar rentabilidad política al gobierno de turno ${ }^{4}$.

La determinación del proceso de institucionalización de la comunicación de masas sobre la realidad social objetiva sólo se puede comprender y probar a largo plazo. Primero, porque es precisamente este plano de la realidad social el que recibe menos determinaciones en un corto tiempo. La realidad social objetiva -reglas y normas preexistentes, acciones de los grupos sociales con mayor poder relativo - es el plano de la realidad desde donde se seleccionan las posibilidades de crear, modificar o controlar normas, valores, acciones y relaciones que puedan tener aceptación y actualización social. La estructura de la realidad social objetiva a finales del siglo XIX y a principios del siglo XX en la Argentina estaba controlada por grupos ideológicamente conservadores. Esto, que dice poco expresado así, es lo que determina los saberes culturales que aparecían en el escenario público, los textos, géneros y modos que eran legitimados para la producción y la distribución masiva; el tipo de personas públicas que se legitimaban o se estigmatizaban en cada uno de estos textos que transmitían ciertos saberes; y por último, también aceptaban o negaban algunos de los usos sociales posibles de estos nuevos medios.

Además, la posibilidad fáctica de que se modifique la realidad social objetiva sólo es posible si los grupos sociales que controlan, producen y modifican las reglas, o no perciban las con-

\footnotetext{
${ }^{2}$ Reglamentación del Servicio Radiotelegráfico, 1917.

${ }^{3}$ Ordenanza Municipal, ciudad de Buenos Aires, 1922.

${ }_{4}^{4}$ Decreto 9.967 (1954) que llamó a licitación para la instalación y explotación de tres redes de radiodifusión. Decreto Ley 15.460 (1957) que reglamentaba el funcionamiento de los servicios de radiodifusión y televisión. Decreto 15.738 (1960) que creó el Consejo Nacional de Radiodifusión y Televisión. Decreło 8.697 (1961) que gravó sobre el ingreso bruto por explotación de los servicios de radiodifusión y televisión.
} 
secuencias mediatas de cierto tipo de acciones, relaciones, valores o normas que cambien la realidad en contra de sus intereses, o que tengan la capacidad de programar las transformaciones que necesiten para alcanzar sus objetivos (Elster, 1989). Los grupos conservadores que utilizaban los medios de comunicación de masas para sus fines, es decir, para confirmar y aumentar el consenso social acerca de sus valores y de sus preferencias, no podían predecir el efecto a largo plazo que los medios y la industria cultural iba a generar sobre las diferentes dimensiones de la realidad social. Incluso, el mismo tipo de ordenamiento que propone la industria cultural, el mercado masivo de la información y la necesidad de una concepción abierta y amplia para su funcionamiento, generó un proceso de democratización funcional o social (Elias, 1995) que está por debajo de la democratización política. En definitiva, la mediatización generó cambios sobre la realidad social objetiva sólo a mediano plazo. Después de varias décadas -tal vez habría que utilizar el concepto de generación - la base social sobre la que se apoyaban los grupos que crearon las reglas en la estructura de la realidad social objetiva, comenzó a transformarse como resultado, entre otros factores de tipo económico, político y social, de una experiencia social y cultural diferente, reproducida por el funcionamiento de los medios de comunicación de masas.

En síntesis, mediatización en tanto el proceso de formación de las rutinas tuvo consecuencias sobre los grupos sociales que controlaron y controlan cada una de las fases del proceso. Políticos, empresarios, militares, profesionales de la cultura, técnicos, público experto o legos crearon, organizaron y se han encontrado, luego, influidos por esta forma de producir y de consumir conocimiento social. En el caso de los grupos dirigentes más conservadores, desde el punto de vista cultural y político, que comenzaron instalando y controlando el sistema de radiodifusión y de televisión en la Argentina, en un plazo de décadas, se encontraron con que estos medios colaboraron con producir una cultura de valores y categorías cognitivas contradictorios a los suyos.

En segundo lugar, hay que tener presente el grado de objetividad de los saberes culturales. Los saberes culturales tienen como atributo básico el hecho de que superan la conciencia de las personas sociales, es decir, se encuentran de modo objetivamente presente, incluso en aquellos momentos en que las personas no los reconocen.

Desde el punto de vista del interés de este trabajo, se debería delimitar el modo en que este conocimiento objetivo, de un tipo muy especial y surgido en un momento histórico específico, tuvo consecuencias sobre la realidad social objetiva. ¿̇Por qué cierto tipo de conocimiento o saber cultural se objetivó en los medios como la radio y la televisión? ¿Qué consecuencias generó esto sobre la realidad social objetiva?

En primer lugar, el conocimiento objetivo depende, para su origen, formación, diseminación y recepción, del tipo de reglas que ordenan las relaciones objetivas. En una primera instancia, este conocimiento es determinado por las condiciones fácticas de las relaciones sociales objetivas. Sólo aparece cierto tipo de conocimiento si los grupos dirigentes -políticos en cualquiera de los tres poderes del Estado, empresarios, dirigentes, intelectuales, etc.-lo permiten o tienen la capacidad de imponerse ante otros intereses. Por ejemplo, el desarrollo pleno de los medios de comunicación no se realizó hasta que la Iglesia Católica modificó su concepción negativa de la industria cultural. 
Las reglas implícitas y explícitas que ha tenido capacidad de establecer la lglesia como agente social, le permitió condicionar el proceso de producción, distribución y recepción del conocimiento en el contexto de los medios. Estas reglas actúan directamente sobre los grupos de dirigentes y de no dirigentes, ya sea porque las consideran reglas producidas legítimamente o porque no pueden modificar la autorregulación que generan en otras personas que toman decisiones.

Las interrelaciones entre las personas que aparecen y las que no pueden hacerlo por la reglas de la realidad social objetiva es un problema importante. Los medios de comunicación de masas se transformaron en un lugar en el cual podía y eran habilitados a aparecer en el escenario público personas de un origen social no aristocrático. Esto era más o menos contradictorio con lo que sucedía en otros órdenes institucionales. Por ejemplo, en el plano educativo, específicamente en el nivel universitario, era muy difícil que personas de origen social humilde, entre los años veinte y treinta, pudiesen descollar. La universidad era un lugar social al que no llegaban las clases menos acomodadas desde el punto de vista económico y social.

Los personajes que absorbió la radio en los años de la década del treinta, por ejemplo, no eran diferentes a los que actuaban en los clubes de barrios o en algún teatro chico del centro de Buenos Aires (Gallotti, 1975: 15 y ss.). Los personajes de la primera década de la radio eran, entonces, reproducciones de los que ya eran populares fuera de ella. El efecto de los personajes de la radio sobre la realidad social objetiva estaba concentrado en su poder de repetición. La habituación y rutinización para la audiencia producía o identificación o proyección en relación con las normas y los valores objetivados en el personaje.

Del mismo modo que con las otras dimensiones analizadas, aunque con más intensidad, la realidad social objetiva modifica e introduce cambios en los textos que aparecerán en la radio y en la televisión para modificar, a su vez, los usos dados por los receptores. Los textos y los géneros usados por la radio se tomaron de los que había en la cultura popular: para entretener con la comedia, con el drama, con la música; para informar con noticias, para dar servicios mediante anuncios publicitarios: todos existían previamente y fueron adaptados a la radio. Sólo a muy largo plazo, después de dos o tres décadas, estos géneros adquieron realmente identificación con la radio. Por ejemplo, en el radioteatro. Para hacerlo es necesario un proceso iterativo y repetitivo, por medio del cual las personas naturalicen la presencia de dicho texto o género. Naturalizar significa que las personas no vean como extraña la presencia del género o del texto en el marco de la cultura y de los saberes a los que se exponen. En síntesis, los efectos de la mediatización sobre la realidad social objetiva se produjo a mediano plazo, aunque las reglas que producen y regulan lo social hayan seleccionado aquellos textos y géneros que les permitió continuar con el proceso de comunicaciones de masas de la radio.

\section{Los efectos de la mediatización sobre la realidad social intersubjetiva}

En este segundo plano de la realidad social, los efectos de la mediatización son más contundentes, desde varios puntos de vista. Las relaciones sociales dinámicas, cambiantes, depen- 
dientes de las percepciones de las personas sociales, de las reglas creadas de manera relacional y de las diferencias de poder social de los participantes en estas relaciones sociales, son más permeables a la influencia de la institucionalización mediática.

En primer lugar, las relaciones intersubjetivas se consideran diferentes ante la posibilidad de tomar conciencia acerca de los cambios que la tecnología de la radio y de la televisión traen para la sociedad. La posibilidad de que se pueda establecer relaciones con personas a las que no podemos percibir directamente, modifica una convicción antropológicamente establecida acerca de la intermediación entre seres humanos.

La radio como artefacto, como aparato doméstico, se transformó, paulatinamente, en parte del ambiente cotidiano de las personas y de las familias. La entrada de la radio a las casas y hogares se realizó motivada por una presentación que definía la radio como un artefacto novedoso para realizar un tipo de práctica poco común hasta ese momento en un ambiente privado: el consumo de música, de información y de entretenimiento. Quienes estaban detrás de esta presentación eran los fabricantes o importadores de los aparatos, que no sólo hacían la programación de la radio sino que también diseñaban los mensajes publicitarios. Pero para que la radio, en tanto artefacto, entrara a la casa, antes debía darse un cambio de concepción acerca de la organización del espacio. La radio fue instalada en el living room o "sala de estar", aunque para que esto sucediese debió cambiar el modo de entender las funciones de este espacio: hasta los años veinte, la "sala de estar" era un recibidor. Sólo se acogía a los visitantes: no se comía, ni se dormía, ni se trabajaba. En cambio, bien entrada la década de los veinte, la sala comenzó a ser un lugar de consumo cultural: libros, diarios, revistas y el aparato de radio (Liernur, 1999:1 16-117). En relación con ese cambio de contexto, entra la radio como técnica en las casas de la clase media argentina. Tardará dos décadas y media, aproximadamente, para llegar a las clases medias bajas y bajas. En 1947, el 54\% de los hogares argentinos tiene un aparato de radio, cifra que en Buenos Aires asciende al $82 \%$ (Ballet, 1999: 24).

Segundo, los saberes culturales que aparecen en el escenario público son cualitativamente diferentes a los que mediatizaban los medios no masificados. Los saberes culturales modificaron sus objetos de saber: cambiaron los sujetos de la enunciación. Aparecen otros objetos (temas) y otros sujetos (personajes). El deporte mediatizado o el fútbol es uno de los cambios más determinantes a corto y a largo plazo para las relaciones sociales.

El conocimiento objetivo tiene una mayor incidencia sobre las relaciones sociales intersubjetivas. En este nivel, el conocimiento objetivo se transforma en parte de estas relaciones, en tanto y en cuanto, las relaciones o interacciones entre personas sociales o entre corporaciones -por medio de personas que las representan - se constituyen por conocimiento simbólico y por la evaluación que las partes hacen de este conocimiento. El ejemplo más claro es el de la determinación que produjo el conocimiento de los medios sobre las relaciones familiares y sobre las relaciones sociales con efecto directo en la política. Las relaciones familiares se vieron afectadas por el conocimiento objetivo porque los padres y los hijos, los hermanos y los abuelos, se encontraron ante un conocimiento que antes no tenían y que no podían compartir. Sobre todo, teniendo en cuenta que este conocimiento 
se realizaba con fines que antes no era habitual que entrara al hogar: la diversión y el entretenimiento. La transmisión del fútbol los días domingos en la radio generó un cambio importante en las relaciones familiares en tiempos de ocio. O la posibilidad de escuchar, un mismo relato de ficción y compartir el mismo tipo de ilusión y de sentimientos activados por este nuevo tipo de conocimiento. Las relaciones sociales que marcan diferencias de posiciones sociales, de prestigio o status, se encontraron afectadas por este conocimiento porque las personas de muchas clases sociales diferentes se exponía a los mismos tipos de conocimientos objetivos, independientemente a las maneras que tenían de interpretarlo. La radio reprodujo, reformuló, expandió y masificó una serie de objetos de saber que estaban antes en el circo, en la opereta popular, en el folletín, en la vida cotidiana.

En tercer lugar, los textos definidos por el género (ver)que los modifica y por las modalidades (serias y no serias) establecen relaciones diferentes con los receptores y dan la posibilidad para que las personas sociales se relacionen de modo diferente entre ellas y que perciban otras posibilidades de relación.

Otro elemento central en el proceso de distanciamiento con los medios, es el tipo de personaje o de persona pública que es identificada por los receptores. En este caso, los cambios están relacionados con el aumento de veces en que el receptor puede interaccionar con el personaje y la representación mediática del personaje. Por otro lado, algo que está relacionado con la tecnología y la organización mediática, la percepción de una relación directa y personal con quien está en los medios (actriz, actor, conductor, periodista), generó problemas de distanciamiento.

Finalmente, los usos posibles de los medios -tecnologías, contenidos, textos y personas - modifican las relaciones y las interacciones en la familia, en el trabajo y en el grupo de amigos o de conocidos.

\section{Las relaciones sociales intersubjetivas. El espacio y el tiempo sociales como coordenadas de relación social}

Los medios de comunicación pública colectiva colaboraron en transformar y en definir la concepciones de espacio y de tiempo sociales que conformaban las relaciones intersubjetivas desde que, por su consumo, se convirtieron en rutinas y en prácticas cotidianas. Sin embargo, esta determinación no sólo se desarrolló sobre las relaciones sociales intersubjetivas, también determinaron a la misma persona social en tanto individualidad y subjetividad. La determinación que el uso y el contacto con estos medios produjo en las relaciones intersubjetivas y en la subjetividad de los seres humanos contemporáneos, se activó colocando límites sobre la acción y sobre la cognición.

A continuación se ejemplificará el modo en que la comunicación pública colectiva modificó las relaciones intersubjetivas y las subjetividades por medio de los cambios activados sobre el espacio y el tiempo sociales.

Espacio. La mediatización colectiva de la sociedad argentina modificó de varias maneras la organización del espacio social que normalmente tenían los habitantes de las ciudades y de las zonas rurales en los años veinte y treinta. En el caso de la radio, no sólo cambió la concepción 
social del espacio social, además, se insertó en la sociedad de los años veinte gracias a los cambios que se estaban dando en esta manera de definir y de organizar el espacio real.

En primer lugar, la radio ocasionó cambios de organización del espacio privado de la casa. Por un lado, la radio fue instalada en un lugar central para la familia de clase media: la sala o el linving room. La modernización del diseño de las casas en la Argentina coincidió con la mercantilización u oferta de aparatos de radio a un precio menor que en un principio. Luego, el diseño de los aparatos de radio fue adaptado para que sirviera de adorno, para ser mostrados a las visitas. En realidad, la radio pasó a ser uno de los objetos que se mostraban a quienes no pertenecían al hogar, es decir, a las visitas. En síntesis, la radio fue introducida en el espacio más compartido y más social del hogar. No sólo compartido por los mismo miembros de la familia, sino por quienes venían a interactuar por ellos. Desde el primer momento, la tecnología doméstica, la producción de saberes culturales, los horarios y las formas estéticas de estos saberes, se adaptaron a la manera en que los contemporáneos estaban habituados a interactuar y a convivir. Pero, poco a poco, la vida cotidiana del consumo de los contenidos de la radio, la manera de exponerse -en grupo, dialogando acerca de lo que escuchaban-modificó aquello que se acostumbraba a hacer hasta entonces en la sala de estar o living room. Al principio, el hecho de que sólo existiera un aparato de radio, definía sólo un momento de exposición y de interacción entre los miembros de la familia. Antes de la radio, las clases medias que vivían en casas con sala de estar la usaban para las actividades individuales: tareas de la escuela de edad escolar, la lectura de entretenimiento y de información en los jóvenes y en los adultos, los juegos de mesa, etc. Estas actividades podían desarrollarse todas juntas y al mismo tiempo, mientras se realizaran en silencio.

En segundo lugar, la radio modificó el espacio público y el de las relaciones de las personas privadas con este espacio. El hombre de a pie, el conjunto de los hombres y de las mujeres que antes de la popularización de la radio no tenían participación en tareas o funciones de gobierno, o que no contaban con los medios económicos para tomar contacto directo con los acontecimientos políticos o culturales públicamente relevantes, experimentan la reorganización social del espacio. Por ejemplo, después de veinte años de que la radio haya aparecido como fenómeno cultural, los argentinos que vivían y trabajaban en el campo (provincias de Buenos Aires, de La Pampa o Santa Fe) podían escuchar los discursos dados por Adolf Hitler, por Benito Mussollini o por Roossevelt. Esto debió producir una experiencia muy diferente del espacio en tanto la percepción directa de la voz y de los detalles no lingüísticos (timbre de voz, tono, inflexiones, etc.) de los discursos acercaban a la casa de campo, o al departamento en la ciudad, acontecimientos que sucedían a miles de kilómetros.

Otra situación que inaugura la radio, y que la televisión después continúa, es la definición de la casa o del hogar como lugar de consumo cultural. En las clases medias bajas y medias, la pequeña biblioteca (o las revistas) fue una primera manera de consumo cultural. Pero de manera contundente, fue la radio instalada en la casa como un medio de escucha colectiva o grupal, con la cercanía de la voz humana y con todas sus dimensiones diferenciadoras y personalizadoras de quienes hablan y de quienes escuchan, la que absorbió la definición de la pauta de consumo cultural entre las clases medias bajas en la Argentina. 
Tiempo. La radio modificó también la organización del tiempo social. Los medios de comunicación en tanto productos de consumo cultural han repetido su forma de establecerse en el entramado social: deben insertarse en la estructura de los tiempos sociales de las sociedades en las que actúan.

Pero la radio no sólo se adaptó a los tiempos de la vida cotidiana de las personas y de las familias en los años veinte y treinta, sino que, luego, modificó los tiempos de ocio, el tiempo libre y laboral de la sociedad. ¿ Cuándo las personas comenzaron a organizar su vida, sus tareas, rutinas y actividades de acuerdo con los tiempos de los programas de radio? En principio, esto debió suceder a partir de que la radio y el consumo de sus programas se convirtieron en una práctica normal y habitual. Pero además, que sea normal y rutinario el hecho de sentarse a escuchar la radio, sea en solitario o en grupo, está condicionado por la cantidad de horas del día que la radio cubría con sus programas. Hay una relación directamente proporcional entre el aumento de horas de producción y de transmisión de contenidos de la radio y la rutinización del consumo de la radio. De acuerdo con la evolución de la programación de la radio, de modo paulatino, ésta fue cubriendo el día y la noche. El hecho de que todas las horas de un día estuviesen cubiertas por algún programa de radio, aceleró el proceso de rutinización de la exposición y de consumo.

Los tiempos sociales que la radio ayudó a estructurar son:

Tiempo de trabajo versus tiempo de ocio. Para las personas que trabajaban fuera de la casa, la radio estaba dentro del tiempo de ocio.

Tiempo de trabajo y tiempo de ocio. Para las amas de casa, por ejemplo, que en los años veinte, treinta y cuarenta permanecían en sus casas poco conectadas con el espacio públi$\mathrm{co}$, la radio les dio la posibilidad de que ambos tiempos no estuvieran separados: el trabajo y el ocio eran dos tiempos simultáneos gracias a que podían escuchar la radio.

Tiempos privados de consumo cultural. No era muy común en la Argentina de los primeros años de la radio, encontrar hogares, sobre todo aquellos que pertenecían a la clase trabajadora, con bibliotecas familiares o con la costumbre de comprar diariamente el periódico o una revista. El consumo cultural de las familias de las clases medias bajas y medias estaba concentrado en los espacios y tiempos públicos. El circo, el teatro, la ópera o las kermeses, los bailes o las bibliotecas populares eran parte del escenario público en el cual se consumían los productos culturales. La casa, el hogar, era un lugar de encuentro familiar, de encuentro con amigos y parientes. La radio profundiza algo que se había manifestado débilmente en la vida de las personas: coloca el consumo cultural cotidiano y rutinario en la misma casa, con horarios establecidos, temas y formatos definidos.

Tiempos de información y de entretenimiento. El tiempo de la familia comenzó a ser dividido entre estas dos categorías. Lo que sólo era un problema de adultos alfabetizados, ahora comenzaba a ser un modo de organizar el tiempo para los menores de la casa. Toda la familia se encuentra ante estos dos tipos de contenidos y géneros, y actualizan más o menos ambas estructuras comunicativas. 
Tiempos semanales y de fin de semana. La radio y después la televisión sólo profundizaron y ayudaron a fijar los usos sociales del tiempo que se acostumbraba. El fútbol, por ejemplo, cumplió una función central para colaborar con este cambio. El deporte mediatizado comenzó, en tanto espectáculo y manifestación para el ocio, con la transmisión que la radio hizo del fútbol de los domingos.

Ampliación de los tiempos de consumo cultural. El hecho de que sólo con estar en la casa se podía escuchar noticias o radioteatro, hizo que aumentara el tiempo dedicado al consumo cultural.

En definitiva, de la misma manera que con la organización del espacio, los medios comenzaron adaptándose a los tiempos sociales normales de la gente. Este tiempo social "premediático" había sido estructurado por las actividades y por las rutinas en las que los medios de comunicación tenían muy poca influencia. Los diarios, las revistas, el teatro, el cine no tenían demasiada incidencia en la organización del tiempo. Unos porque no eran consumidos por muchas personas, aunque sí tenían cierta periodicidad; otros, porque, aunque consumidos por un gran público, no contaban con la suficiente periodicidad para que se forme una rutina. Una de las rutinas más importantes fue el hecho de que profundizó el proceso de privatización del consumo cultural. Aumentó el tiempo del consumo cultural en la casa, es decir, en el ámbito privado de la vida cotidiana, estaba concentrado en la lectura (ver lectura, vida privada). Pero esto no fue, al principio, algo común a todas los estamentos sociales. La presencia de bibliotecas en los hogares, la compra del diario y la práctica de la lectura en las familias argentinas llegó después de que la radio ya fuese un medio cultural instalado en las casas. La radio en la casa significó la posibilidad real de consumir, primero música, después información periodística (la lectura de los diarios La Nación, La Razón o La Prensa en programas organizados por las mismas empresas editoras) y finalmente, lo más importante, el entretenimiento de ficción (radioteatro, por ejemplo).

\section{Los efectos de la mediatización sobre la subjetividad personal}

Varias son las transformaciones generadas por la radio sobre la subjetividad social de las personas. La subjetividad social o la persona social tiene varias dimensiones: el pensamiento, la acción o la conducta, sea racional o emocional, el cuerpo.

\section{Conductas racionales y emocionales}

El efecto más directo de la mediatización es sobre la acción o la conducta de las personas sociales que cumplen papeles de receptores. Esto produce ciertos refuerzos (Elster, 1989: 55) sobre todo en el plano del inconsciente, ya que se originan rutinas de las cuales las personas se transforman en dependientes.

Desde que las personas sociales tomaron contacto con la radio, y luego con la televisión, comenzaron a organizar acciones tanto de tipo racional como emocional, para interaccionar 
con las tecnologías, con los textos, los contenidos y las personas que aparecen como personajes de esos textos.

Los aspectos emocionales de la conducta humana suelen ser menos tratados y analizados que los de orden racional. Quedan a salvo de este olvido pocos investigadores de relevancia dentro de las ciencias sociales. La teoría social, y dentro de ella, los estudios de comunicación, no le ha concedido el lugar que debería a las emociones y a los estados afectivos. Pero no es posible explicar los efectos de la mediatización sin hacer referencia a los cambios que ésta ocasionó en la organización de las emociones en los seres humanos.

En primer lugar es necesario decir que desde el primer momento, la radio fue un instrumento de mediatización de emociones. Las personas fueron atraídas por el nuevo medio gracias a sus modalidades afectivas. Los personajes de los programas identificados por las características connotativas y afectivas de su voz, la atracción por la música instrumental o vocal, de todo tipo y época, activaron y acostumbraron a los receptores a que la comunicación de masas no sería todo lo seria y lo racional que parecía ser en el consumo del diario o del periódico.

Los receptores comenzaron a habituarse a la radio y al mismo tiempo este hábito se relacionó con la reproducción de emociones que los personajes de la radio, la música y los locutores presentaban. La gente que constituyó el público de la radio aprendió la manera de reproducir las emociones en contacto con los textos sonoros, la música, los locutores y los personajes de ficción.

Acciones emocionales que surgen de las relaciones fortuitas con los personajes. Al principio la mediatización sólo era una novedad tecnológica. Las personas se transformaban en oyentes porque les atraía la técnica en sí misma. Les llamaba la atención y les gratificaba la posibilidad de que el sonido articulado o que las imágenes en movimiento se transmitieran desde un lugar lejano.

En resumen, la radio -y del mismo modo, luego la televisión - produjeron situaciones sociales nuevas para la expresión y experiencia de emociones, la mayoría de las veces, sobre todo en las primeras décadas, para ser compartidas en un grupo social.

Experiencias personales: cómo pensar con los medios.

Las experiencias personales de los hombres y mujeres sufren reorganizaciones a partir de tomar contacto con la radio. En primer lugar, la radio es el primer medio con una modalidad de comunicación diferente a la prensa escrita, a la cultura popular (teatro, circo, baile, etc.) y al cine: se puede permanecer en la propia casa, pero al mismo tiempo, permite conectarse continuamente con una realidad externa al hogar. Esta fue una experiencia conmocionante para quienes se encontraron como primera generación ante la radio. Del mismo modo sucedió con la televisión: el impacto emocional no buscado que ocasionaba la propia estructura de competencias comunicativas fue central para modificar las experiencias humanas. La posibilidad de que la voz humana y el sonido 
viajara en el espacio fue la primera experiencia conmocionante. Luego, la televisión puso en duda el sentido común con la posibilidad de que se pudiesen ver imágenes de personas en movimiento que estaban a una distancia no perceptible por el ojo humano.

Segundo, la experiencia de escuchar a las personas que hablaban en la radio y de formarse una conciencia acerca de algún tipo de característica individual y humana de esta persona. Las personas que escuchaban la radio idealizaban a quienes actuaban en el medio a partir de signos también usados en la comunicación cara a cara, por ejemplo, el timbre o el tono de voz. La experiencia de escuchar a alguien que se encontraba en el mismo momento en que se producía la comunicación a una distancia que superaba las competencias físicas del cuerpo, generó una mezcla de atracción y de admiración, sobre todo en los primeros años de la radio y en los comienzos de la televisión.

Hay dos consecuencias importantes relacionadas con esta experiencia: por un lado, la familiaridad con que la gente trata a los personajes reales y ficticios de la radio; en segundo lugar, el alto grado de credibilidad que surge de esta habituación y familiaridad.

En tercer lugar, los oyentes de radio comenzaron a tener una experiencia de no separación entre los personajes que aparecían en la radio y las personas reales, es decir, los profesionales que actuaban. La desdiferenciación entre la ficción y la realidad fue una experiencia muy profunda. El público reaccionaba de forma violenta cuando se encontraba con los personajes "malos" de los radioteatros y de modo amigable cuando veía o hablaba con los personajes "buenos" (Ulanovsky, Merkin, Panno, Tijman, 1996:72-73).

Pero no es posible comprender la experiencia de desdiferenciación entre lo ficticio y lo real sin la experiencia de la familiaridad y la credibilidad que originaban los personajes de la radio. No era posible alcanzar tanta popularidad ni generar conductas emocionales tan intensas si no fuese que las personas del público mantenían una relación cotidiana, que les permitía creer en las situaciones vividas en los programas e identificarse o proyectarse en ellas. Se puede afirmar que existía, al principio del desarrollo de los medios, una relación coherente entre expectativas de los oyentes y lo que percibía de los personajes.

Otra experiencia que fue profundizada por el proceso de mediatización de la radio fue el hecho de que el modelo real de consumo cultural se transformó en uno virtual. El cine combinó atributos de ambos modelos: quienes hacían el espectáculo no estaban en presencia de quienes gozaban con él, pero esto se olvidaba rápidamente: la presencia de un público en la sala de cine producía como consecuencia la experiencia de estar ante un espectáculo real. La radio ayudó a desestructurar esta rutina que venía de la época en que el teatro, la opereta y el circo eran más populares que el cine.

En cuarto lugar, los géneros y las formas estéticas producidas para la radio y que tomó simplemente la televisión, produjo una experiencia diferente sobre los procesos de autoridad y de legitimación social. La costumbre de ironizar sobre el poder y sobre la autoridad no es algo originado en la 
comunicación de masas, pero se podría decir que es una experiencia multiplicada y convertida en algo común y habitual a partir de que los medios de difusión colectiva comenzaron a funcionar de modo normal. Este proceso de cambio en la aceptación de la autoridad está relacionado directamente con la experiencia de familiaridad y de cercanía con los personajes que actuaban en la radio y luego en la televisión. La radio y la televisión fueron usados, como medios de exposición, en el lugar del cine. Este cambio de rutina produjo, poco a poco, la aceptación más inconsciente de las creencias y de las normas que aparecían como validadas en los textos y contenidos de la radio y de la televisión.

\section{CONCLUSIONES}

El grado propedéutico del análisis social e histórico realizado sobre los procesos de mediatización o de institucionalización mediática generó la posibilidad de pensar en que los efectos de los medios deberían tratar de estudiarse desde modelos teóricos, epistemológicos y metodológicos diferentes. Primero, porque los estudios de efectos de los medios no pueden realizarse sin prestar atención al modo en que se han institucionalizado la comunicación de masas en la sociedad. La institucionalización o mediatización social es lo que produce el proceso de distanciamiento que los receptores tienen con los medios (Elizalde, 1999a) y es lo que agrega significado a cualquier tipo de efecto cognitivo, racional o emocional. Segundo, la institucionalización es un proceso social que actúa en el plano del cognitivo, consciente e inconsciente, y que activa procesos de conducta, tanto racional como emocional. Lo más importante en este proceso son los alcances de la rutinización en la relación (Elizalde, 2000) que no se puede dejar de estudiar como proceso de institucionalización. Tercero, los intentos por decidir si los medios influyen, por ejemplo, en la conducta sexual, agresiva, pacífica, o si tienen la capacidad de cambiar la imagen pública de un político, etc. no tienen sentido si no se los realiza dentro del proceso de institucionalición o mediatización. Cualquier decisión de los receptores, ya sea consciente como inconsciente, está producida por este proceso de mediatización.

En definitiva, los cambios que los medios han producido y producen en la realidad social, no se desarrollan dentro de un vacío social. Por el contrario, la actividad de los medios -desde cualquiera de sus dimensiones -tecnología, saber cultural, textos, personajes, usos - se explica finalmente sólo dentro de un campo social de relaciones (objetivas, intersubjetivas, subjetivas). El hecho de que cada una de las dimensiones identificadas por los estudios de recepción produzcan o frenen cambios que se están por producir en la realidad social, no puede explicarse sin antes objetivar el contexto no mediático en el que actúan, piensan y sienten tanto los productores como los receptores.

Los modelos experimentales que estudian los efectos suelen no considerar los antecedentes culturales, sociales y personales de quienes recepcionan. Por eso generan resultados más o menos erráticos en relación con la capacidad de los medios de producir efectos. Sin lugar a duda, en los años veinte-de acuerdo con la explicación de este trabajo-los efectos que produjo la radio estaban definidos por las condiciones mediáticas y no mediáticas del momento: ya sea desde el tipo de definición de técnica aceptada por la sociedad, pasando por los saberes culturales objetivos, legitimados y no legitimados, por los personajes que aparecían o los que no aparecían en el escenario público, hasta los textos y modos en que los saberes y personajes eran organizados. 


\section{REFERENCIAS BIBLIOGRÁFICAS}

= Ballet, A. (1999): "La casa para todos: grandeza y miseria de la vivienda masiva", en en Devoto y Madero (dir.) Historia de la vida privada en la Argentina. 1930-1980. Buenos Aires: Taurus Ediciones, pp. 19-49.

" Bourdieu, P. (1983): "Campo intelectual, campo de poder y habitus de clase", en Campo del poder y campo intelectual, Buenos Aires.

= Bourdieu, P. (1991): Sentido práctico, Madrid: Taurus Ediciones.

= Bourdieu, P., Wacquant, J.D. (1995): Respuestas por una antropología reflexiva, México: Editorial Grijalbo.

= Devoto, F., Madero, M. (1999): Historia de la vida privada en la Argentina. La Argentina plural: 1870-1930", Buenos Aires: Taurus Ediciones.

= Elias, N. (1989): Sobre el tiempo, México: Fondo de Cultura Económica.

- Elias, N. (1990): Compromiso y distanciamiento. Ensayos de sociología del conocimiento, Barcelona: Ediciones Península.

= Elias, N. (1995); Sociología fundamental, Barcelona: Gedisa.

= Elizalde, L.H. (1998): "Los jóvenes y las tecnologías de la comunicación y de la información. Hacia una etnografía de los entornos mediáticos", en ZER, n 5, pp.121-156.

= Elizalde, L.H. $\left(1999^{\circ}\right)$ : "Los jóvenes y sus relaciones cotidianas con los medios. Una aproximación teórica y metodológica", Colección Cuadernos Austral, Buenos Aires: Facultad de Ciencias de la Información, Universidad Austral.

= Elizalde, L. H. (1999b): "Recepción y sentido común. Estructura de los acontecimientos mediáticos conmocionantes y pautas de recepción", en Estudios sobre el mensaje periodistico, n 5, pp. 169-206.

E Elizalde, L.H. (2000): "Factores y condiciones de la comunicación audiovisual. Su definición desde el ámbito de la recepción.", en ZER, n 9, pp.185-236.

w Elizalde, L.H. (2002): "Radio y televisión", en Nueva Historia de la Nación Argentina, tomo 9: "La Argentina del siglo XX", Planeta: Buenos Aires, pp. 363-394.

= Felson, R. (1996): "Mass Media Effects on Violent Behavior", Annual Review of Sociology, vol. 22, pp. 103-128.

= Gunter, B. (1996): "Acerca de la violencia de los media", en Bryant y Zillmann, Los efectos de los medios de comunicación. Investigaciones y teorías, Barcelona: Paidós, , pp. 223-286.

" Habermas, J. (1998): Facticidad y validez. Sobre el derecho y el Estado democrático en términos de teoría del discurso, Madrid: Editorial Trotta.

= Habermas, J. (1988): Lógica de las ciencias sociales, Madrid: Tecnos.

= Innis, H. (1951): "Industrialism and Cultural Values", The American Economic Review, vol. 41, Issue 2, pp. $201-209$.

"Innis, H. (1942) "The Newspaper in Economic Develoment", The Journal of Economics History, vol. 2, Issue Supplement: The Tasks of Economic History (Dec.), pp. 1-33.

= Liernur, J. F. (1999): "Casas y jardines. Las construcciones del dispositivo doméstico moderno", en Devoto y Madero (dir.) Historia de la vida privada en la Argentina. La Argentina plural: 1870-1930, Buenos Aires: Taurus Ediciones, pp. $99-139$.

- Lorenz, K. (1993): La ciencia natural del hombre. El 'manuscrito de Rusia'. Introducción al estudio comparado del comportamiento. Barcelona: Tusquets Editores. 
= Luhmann, N., De Giorgi. R. (1993): Teoría de la sociedad, México: Universidad de Guadalajara. Universidad Iberoamericana. Instituto Tecnológico y de Estudios Superiores de Occidente.

= Mcluhan, M. (1996): "El medio es el mensaje", en Comprender los medios de comunicación. Las extensiones del ser humano. Barcelona: Paidós.

= Ong,W. (1967): "Breakthrough in Communications", en In the human grain. Further explorations of contemporary culture, New York: The Macmillan Company, pp. 1-16.

= Touraine, A. (1995): Producción de la sociedad, México: Universidad Nacional Autónoma de México. Instituto de Investigaciones Sociales. Instituto Francés de América Latina. 